\title{
Carcinoma de células pequeñas extrapulmonar de mama. Reporte de caso
}

\author{
Eduardo Reyna-Villasmil, ${ }^{1}$ (D) Valeria Fernández-Casado, ${ }^{2}$ (D) Florance Cárdenas-Palomino. ${ }^{2}$
}

\begin{abstract}
RESUMEN
El carcinoma de células pequeñas representa $20 \%$ de los cánceres de pulmón, raramente ocurre en otros sitios. El carcinoma de células pequeñas extrapulmonar es agresivo, con propensión a la diseminación regional y a distancia. Es una neoplasia poco frecuente en mama. Aunque la apariencia clínica es inespecifica, a menudo responde bien a la terapia y tiene buen pronóstico de supervivencia. Se presenta el caso de mujer de 50 años con carcinoma de células pequeñas extrapulmonar de mama. El examen físico mostró lesión de $4 \times 3 \times 3$ centímetros confirmada por resonancia magnética de la mama izquierda. El diagnóstico se realizó mediante biopsia que mostró las características células pequeñas, redondas, similares a linfocito, con núcleos hipercromáticos y escaso citoplasma compatible con carcinoma de células pequeñas de mama. La paciente fue tratada con quimioterapia antes de ser sometida a mastectomía total y resección de los ganglios linfáticos.
\end{abstract}

Palabras clave: Mama, Carcinoma de mama, Carcinoma extrapulmonar de células pequeñas, Cáncer de células pequeñas.

\section{Extrapulmonary small cell carcinoma of the breast. Case report SUMMARY}

Small cell carcinoma represents 20\% of lung cancers, rarely occurs in other sites. Extrapulmonary small cell carcinoma is aggressive with a propensity for regional and distant dissemination. This type of carcinoma is a rare neoplasm in the breast. Although the clinical appearance is nonspecific, it often responds well to therapy and has a good prognosis of survival. We present the case of a 50-year-old woman with extrapulmonary small cell carcinoma of the breast. Physical examination showed a lesion of $4 \times 3 \times 3$ centimeters confirmed by magnetic resonance imaging of left breast. Diagnosis was made by a core biopsy that showed the characteristics of small, round, lymphocyte-like cells with hyperchromatic nuclei and scarce cytoplasm compatible with small cell carcinoma of the breast. Patient was treated with chemotherapy before undergoing total mastectomy and resection of the lymph nodes.

Keywords: Breast, Breast carcinoma, Extrapulmonary small cell carcinoma, Small cell cancer.

\section{INTRODUCCIÓN}

El carcinoma de células pequeñas (CCP) es un tumor que habitualmente se localiza en el pulmón (1). El CCP extrapulmonar es una neoplasia maligna poco frecuente que se describió por primera vez en 1930 como una entidad patológica clínica diferente al de

\footnotetext{
'Doctor en Medicina Clínica. Especialista en Ginecología y Obstetricia. Servicio de Obstetricia y Ginecología.Hospital Central "Dr. Urquinaona". Maracaibo. Estado Zulia. Venezuela. ${ }^{2}$ Especialista en Cirugía. Servicio de Cirugía. Hospital "San Vicente de Paul". Ibarra. Ecuador. Correo para correspondencia: sippenbauch@gmail.com
}

Forma de citar este artículo: Reyna-Villasmil E, Fernández-Casado V, Cárdenas-Palomino F. Carcinoma de células pequeñas extrapulmonares de mama. Reporte de caso. Rev Obstet Ginecol Venez. 2022; 82(1): 118-122. https://doi.org/10.51288/00820114 pulmón $(2,3)$. Tiene una incidencia de $0,1 \%$ a $0,4 \%$ en las neoplasias generales y $2,5 \%$ a $5 \%$ en los CCP. Existen informes de numerosas zonas de aparición, siendo los más frecuentes cabeza y cuello, aparato digestivo y sistema genitourinario. Ocasionalmente, se han notificado casos en mama, tiroides, piel y timo, lo cual representa un desafío tanto diagnóstico como terapéutico (3).

El CCP es uno de los tipos menos frecuentes del cáncer de mama (menos del $1 \%$ ). La historia natural de este carcinoma aún no ha sido totalmente descubierta y, por lo tanto, existen pocos datos sobre su comportamiento clínico y tratamiento óptimo $(2,4)$. Se presenta un caso de carcinoma de células pequeñas extrapulmonar de mama. 


\section{CASO CLÍNICO}

Se trata de una paciente femenina de 50 años, que asistió a la consulta por presentar aumento de volumen de la mama izquierda, continuo, progresivo y que no mejoraba con ningún tipo de medicación, de aproximadamente 9 meses de evolución. La paciente negaba antecedentes personales de hipertensión, diabetes mellitus, tuberculosis o cualquier enfermedad crónica o antecedentes familiares de importancia. También negaba antecedentes de consumo de tabaco, alcohol o drogas recreacionales.

Al examen físico se observó un tumor retroareolar en mama izquierda, de aproximadamente 6 centímetros, asociada con aumento de volumen de los ganglios linfáticos axilares ipsilaterales. El resto del examen físico estaba normal. La ecografía, mamografía y resonancia magnética, demostraron la presencia de un nódulo de $4 \times 3 \times 3$ centímetros localizado en la región retroareolar de la mama izquierda (figura 1). También confirmaron los hallazgos junto a un nódulo satélite de 1,5 centímetros y dos ganglios axilares que estaban aumentados de tamaño (2,5 y 1,9 centímetros, respectivamente). No se encontraron lesiones pulmonares sugestivas de posible tumor pulmonar primario, linfadenopatías mediastinales o metástasis en otras regiones evaluadas por tomografía computarizada corporal total y cintigrama óseo.

En vista del cuadro clínico, se decidió realizar biopsia con aguja gruesa de la lesión, la cual demostró presencia de células pequeñas, redondeadas u ovales, similares a linfocitos con núcleos hipercromáticos, escaso citoplasma, mitosis frecuentes y nucléolos pequeños, compatible con CCP (figura 2). Las células fueron intensamente positivas para citokeratinas, sinaptofisina y cromogranina A y negativas para p53, Her2/Neu y receptores de estrógenos y progesterona. El índice Ki67 fue de 80 \%. Las pruebas bioquímicas sanguíneas, electrocardiograma y los valores de antígeno carcinoembriogénico y CA 19-9 estaban todos

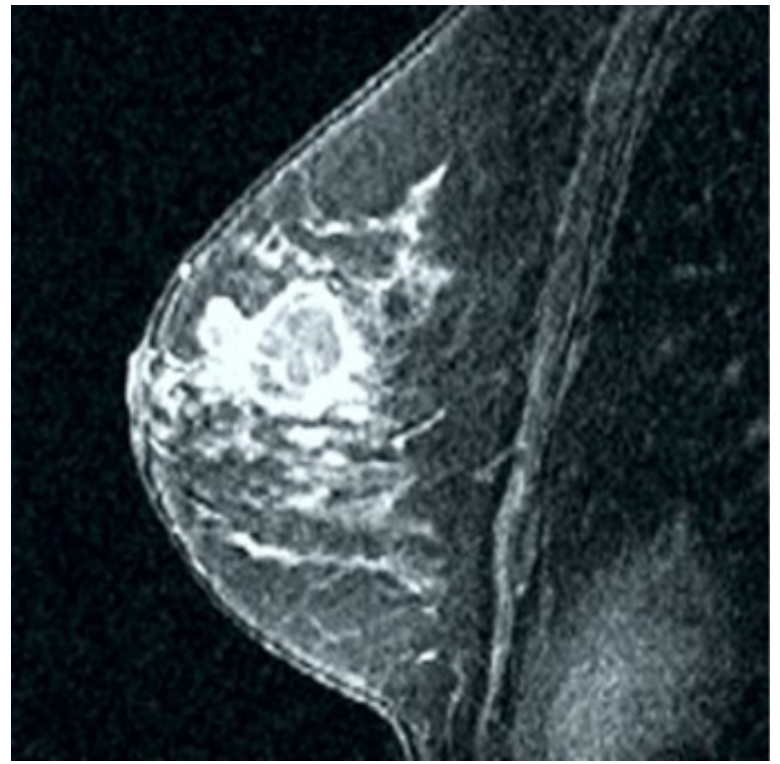

Figura 1. Imagen de resonancia magnética de la mama izquierda donde se observa el nódulo retro-areolar.

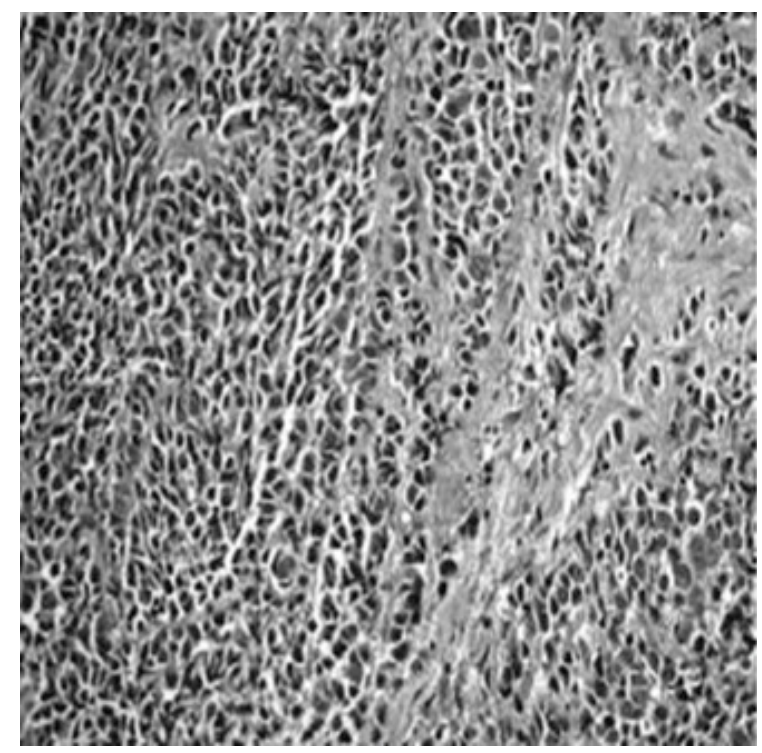

Figura 2. Células pequeñas, redondeadas u ovales, similares a linfocitos con núcleos hipercromáticos, escaso citoplasma, mitosis frecuentes y nucléolos pequeños, compatible con carcinoma de células pequeñas de mama. Coloración hematoxilina-eosina. 
dentro de límites normales, descartando la posibilidad de síndrome paraneoplásico. Estos hallazgos llevaron al diagnóstico de CCP extrapulmonar de mama, con extensión a ganglios linfáticos.

Debido al estadio localmente avanzado de la enfermedad, la paciente fue sometida inicialmente a quimioterapia con cisplatino $\left(75 \mathrm{mg} / \mathrm{m}^{2}\right)$ y etopósido $\left(100 \mathrm{mg} / \mathrm{m}^{2}\right)$ endovenosos cada 21 días por 5 ciclos. Las imágenes de la resonancia magnética realizada después del final la quimioterapia demostraron regresión del $90 \%$ del tumor luego del tratamiento. Treinta días después del final del tratamiento se realizó mastectomía total con disección de los ganglios linfáticos ipsilaterales. La evaluación anatomopatológica confirmó CCP de mama con respuesta a la quimioterapia, sin evidencia de enfermedad residual en el parénquima mamario y en los ganglios axilares. La radioterapia adyuvante de la pared torácica y los ganglios linfáticos supraclaviculares se realizó junto con la irradiación profiláctica cerebral. Luego de 21 meses, los controles postratamiento no han demostrado evidencia de recurrencia de la enfermedad local o sistémica.

\section{DISCUSIÓN}

E1 CCP representa alrededor de1 $20 \%-25 \%$ de todos los carcinomas broncogénicos; solo el 2,5 \% - $4 \%$ surge en sitios extrapulmonares y es considerado como una neoplasia agresiva (1). Su aparición se ha reportado, con mayor frecuencia, en senos paranasales, cavidad nasal, glándulas salivales, glándula tiroides, laringe y tráquea, rara vez, en ovarios, próstata, vejiga urinaria, cuello uterino y mama (3). Existen pocos estudios sobre CCP extrapulmonar localizado en mama. La edad promedio de aparición es de 55 años (entre 41 y 70 años), apareciendo como un tumor clínicamente palpable y dos terceras partes de las pacientes presentan invasión de los ganglios linfáticos al momento del diagnóstico (4-6).
Aunque se han postulado diversas teorías, el origen del CCP no está claro. Se considera que se origina a partir de células neuroectodérmicas preexistentes, células madre epiteliales pluripotentes o células precursoras de adenocarcinoma. Se ha propuesto también que estos tumores se originan a partir de células primitivas totipotentes que pueden conducir a diferenciación dual o múltiple, incluida una mezcla de células neoplásicas pequeñas, células escamosas y células adenocarcinomatosas. Algunas anomalías citogenéticas, como la inestabilidad de los microsatélites, la pérdida de heterocigosidad y la eliminación o pérdida de cromosomas, también han sido reportadas en CCP extrapulmonar de tracto gastrointestinal, vesícula biliar, cuello uterino, vejiga urinaria y mama (3).

El hábito tabáquico y alcohólico se han postulado como factores de riesgo, pero esta asociación no se ha podido verificar. La mayoría de los pacientes se presentan con un tumor mamario palpable y/o linfadenopatía axilar y pueden acompañarse de síndromes paraneoplásicos (secreción inapropiada de hormona adenocorticotropa o antidiurética) (6). Las características mamográficas, ecográficas y de resonancia magnética han sido descritas como inespecíficas, ya que son similares a los de otros carcinomas mamarios, por lo que el diagnóstico final se realiza únicamente mediante biopsia (2). Para establecer el diagnóstico de CCP de mama se debe tener en cuenta que este no sea metastásico. La evaluación debe incluir estudios por imágenes cerebrales y gammagrafía ósea para excluir afección del sistema nervioso central y metástasis óseas. Se sugiere practicar aspirado de médula ósea especialmente para aquellos pacientes con citopenia (6).

Los CCP, independientemente del sitio de origen, comparten similitudes en sus características morfológicas. Las células son pequeñas redondas $u$ ovaladas, con núcleos densos, nucléolos discretos y citoplasma escaso. Tienen alto índice mitótico, con 
crecimiento laminar, patrones trabeculares y pueden contener áreas de necrosis $(5,7)$. Generalmente, puede asociarse con evidencia histológica de carcinoma ductal in situ y áreas de diferenciación ductal, lobular o papilar. La inmunohistoquímica, así como la histología, se consideran el sello del diagnóstico patológico. No es sorprendente que las células posean tinciones positivas para los marcadores neuroendocrinos comunes como enolasa específica de la neurona, sinaptofisina y marcador específico de la diferenciación neuroendocrina, la cromogranina-A. Cerca del $50 \%$ de los tumores presentan receptores hormonales positivos. La sobreexpresión de HER2/ Neu no ha sido descrita (7).

Los diagnósticos diferenciales incluyen: CCP metastásico, tumor de células de Merkel, linfoma primario o secundario, tumor carcinoide y melanoma maligno metastásico (6). El carcinoma de células de Merkel es morfológicamente similar, pero muestra una coloración inmunohistoquímica característica de CK20 perinuclear. El melanoma y el linfoma se pueden identificar fácilmente por sus marcadores específicos S-100, HMB-45 y CD45 (6-8).

El CCP de pulmón es un tumor de crecimiento muy rápido y con potencial de metástasis a distancia, incluso en el curso temprano de la enfermedad (1). Por lo general, produce metástasis a los huesos, ganglios linfáticos, glándula suprarrenal, hígado, cavidad oral, lengua, encía, glándula parótida y cerebro. El CCP extrapulmonar es una entidad clínico-patológica con un curso clínico agresivo similar al de pulmón y por ser de naturaleza recurrente, tiene mal pronóstico (9). No obstante, se debe diferenciar entre los casos con enfermedad localizada que presentan una supervivencia mayor de 8 - 22 meses. Los pacientes con enfermedad diseminada tienen tasas de supervivencia menores, desde 3 - 8,5 meses (5). Las pacientes con CCP extrapulmonar de mama tienen pronóstico más favorable, especialmente si se diagnostican en etapas tempranas, con tasas de supervivencia a los 3 años del $60 \%$, mientras que solo el $7 \%$ de los pacientes con origen gastrointestinal continúan vivos $(2,5)$.

No existe consenso con respecto a los regímenes de tratamiento y existen diferencias entre los casos con enfermedad localizada y diseminada. La cirugía desempeña un papel más importante en CCP extrapulmonar que en el pulmonar, especialmente en las pacientes con enfermedad mamaria, pero debe ser apoyada con quimioterapia y radioterapia. El tratamiento ha evolucionado desde la cirugía radical a los tratamientos de quimioterapia adyuvantes con esquemas similares al CCP del pulmón. La terapia multimodal, con la combinación de cirugía radical o quimioterapia se prefiere, incluso en etapas tempranas. El esquema de quimioterapia más efectivo para el tratamiento es la combinación cisplatino más etopósido, con una tasa de respuesta del $69 \%$ (10), como se demostró en este caso. La asociación de doxorubicina no mejora la tasa de supervivencia (11). Ya que la resolución es posible en enfermedad limitada, se recomienda el tratamiento multimodal intensivo.

La radioterapia debe cubrir la lesión primaria e incluir los ganglios linfáticos regionales. El uso de radioterapia craneal profiláctica en pacientes con CCP del pulmón ha demostrado ser benéfico para la supervivencia general, así como para la reducción del número de metástasis cerebrales. Debido al pequeño número de casos de CCP de mama publicados hasta la fecha, hace imposible ofrecer recomendaciones sobre el papel de la radioterapia craneal profiláctica en este grupo de pacientes (12). A diferencia de lo realizado en este caso, la mayoría de los casos publicados han optado por no utilizar la radioterapia profiláctica. Quizá esta podría tener indicaciones específicas en pacientes que presentan enfermedad avanzada en el momento del diagnóstico.

En conclusión, el CCP de la mama es una neoplasia 
para la cual no se ha establecido un protocolo de tratamiento efectivo, debido al pequeño número de casos reportados. Basado en el estadio clínico, la cirugía y la quimioterapia adyuvante, con o sin radioterapia profiláctica, parece ser el tratamiento de elección.

\section{Sin conflictos de interés.}

\section{REFERENCIAS}

1. Martin F, Molina J, Martin T. Cáncer pulmonar: avances en el siglo XXI. Gac Med Caracas. 2010; 118(3): 183 $-188$.

2. Joyce EA, Kavanagh J, Sheehy N, Beddy P, O'Keeffe SA. Imaging features of extrapulmonary small cell carcinoma. Clin Radiol. 2013; 68(9):953-961. doi: 10.1016/j.crad.2013.04.006.

3. Patibandla JR, Fehniger JE, Levine DA, Jelinic P. Small cell cancers of the female genital tract: Molecular and clinical aspects. Gynecol Oncol. 2018; 149(2):420-427. doi: 10.1016/j.ygyno.2018.02.004.

4. Abou Dalle I, Abbas J, Boulos F, Salem Z, Assi HI. Primary small cell carcinoma of the breast: a case report. J Med Case Rep. 2017; 11(1):290. doi: 10.1186/ s13256-017-1467-0.

5. Brammer JE, Lulla P, Lynch GR. Retrospective review of extra-pulmonary small cell carcinoma and prognostic factors. Int J Clin Oncol. 2014; 19(5):822-828. doi: 10.1007/s10147-013-0626-6.

6. Walenkamp AM, Sonke GS, Sleijfer DT. Clinical and therapeutic aspects of extrapulmonary small cell carcinoma. Cancer Treat Rev. 2009; 35(3):228-236. doi: 10.1016/j.ctrv.2008.10.007.
7. Konopka KE. Diagnostic Pathology of Lung Cancer. Semin Respir Crit Care Med. 2016; 37(5):681-688. doi: 10.1055/s-0036-1592172.

8. Pacheco C, Padrón Y, Herrera J, Muñoz L, Moreno L, Gómez A, et al. Linfoma primario de mama: presentación de 3 casos revisión de la literatura. Rev Venez Oncol. 2002; 14(1):35-39.

9. Kanat O, Kilickap S, Korkmaz T, Ustaalioglu Oven BB, Canhoroz M, Cubukcu E, et al. Primary small cell carcinoma of the breast: report of seven cases and review of the literature. Tumori. 2011; 97(4):473-478. doi: 10.1700/950.10400.

10. Shabbir SM, Raza SM, Bhatti SM. Primary Mammary Small Cell Carcinoma. J Coll Physicians Surg Pak. 2018; 28(6):S112-S113. doi: 10.29271/jcpsp.2018.06. S112.

11. Yumiba S, Asakura T, Okada T, Satoh M, Nin M, Tsujihata M. [Etoposide and Carboplatin Effective for Treatment of Small Cell Carcinoma of Prostate:AReport of Two Cases]. Hinyokika Kiyo. 2016; 62(12):639-645. Japonés. doi: 10.14989/ActaUrolJap_62_12_639.

12. Murata T, Fujii M, Akahane K, Oda K, Ohama T, Yatabe $\mathrm{Y}$, et al. Multidisciplinary management of small cell carcinoma of the breast: a case report. Nagoya J Med Sci [Internet]. 2014 [consultado agosto de 2018]; 76(1-2):173-180. Disponible en: https://www.ncbi.nlm. nih.gov/pmc/articles/PMC4345717/pdf/2186-3326-760173.pdf 